\title{
Benzedura na Estratégia Saúde da Família: perspectivas de profissionais da enfermagem
}

Blessing in the Family Health Strategy: perspectives of nursing professionals

Benzedura en la Estrategia Salud de la Familia: perspectivas de profesionales de la enfermería

Recebido: 18/09/2019

Aprovado: 05/11/2020

Publicado: 17/02/2020

\author{
Janaína Aparecida Maia Silva ${ }^{1}$ \\ Luiza Maria de Assunção ${ }^{2}$ \\ Leiner Resende Rodrigues ${ }^{3}$
}

Esta é uma pesquisa quantiqualitativa de caráter descritivo e exploratório, que tem como objetivo caracterizar os profissionais de enfermagem e apresentar sua perspectiva sobre a benzedura junto à Estratégia Saúde da Família em município mineiro. Participaram 44 profissionais de enfermagem na fase de avaliação de perfil e conhecimento de benzedura, aplicando-se sete entrevistas audiogravadas para um segundo momento do estudo. Constatouse que $90,9 \%$ dos informantes são do sexo feminino e $56,9 \%$ de cor branca, $43,1 \%$ católicos, 27,3 \% kardecistas e \% 68,2 usam a benzedura. Da análise temática emergiram duas categorias: Saúde e práticas espirituais/religiosas; Relações entre benzedura e práticas de saúde e cuidado. A benzedura é percebida como uma alternativa na resolutividade, na hospitalidade e atenção.

Descritores: Atenção primária à saúde; Espiritualidade; Humanização da assistência.

This is a quantiqualitative, descriptive and exploratory research, which aims to characterize the nursing profesisonals and present their perspective on blessing along with the Family Health Strategy in a municipality of Minas Gerais state. Participants were 44 nursing professionals in the profile evaluation phase and blessing knowledge, applying seven audio-recorded interviews for a second phase of the study. It was found that $90.9 \%$ of the respondents are female and 56.9\% white, 43.1\% Catholic, 27.3\% Kardecists and 68.2\% make use of blessing. From the thematic analysis, two categories emerged: Health and spiritual/religious practices; Relationships between blessing and health practices and care. Blessing is perceived as an alternative in solving, hospitality and care.

Descriptors: Primary health care; Spirituality; Humanization of assistance.

Esta es una investigación cuántica de carácter descriptivo y exploratorio, que tiene como objetivo caracterizar a los profesionales de enfermería y presentar su perspectiva sobre la benzedura junto a la Estrategia Salud de la Familia en municipio minero. Participaron 44 profesionales de enfermería en la fase de evaluación de perfil y conocimiento de benzedura y, se aplicó siete entrevistas audio grabadas para un segundo momento del estudio. Se constató que el 90,9\% de los informadores son mujeres y el 56,9\% de color blanco, el 43,1\% católicos, el 27,3 \% kardecistas y el 68,2 \% usan la benzedura. Del análisis temático surgieron dos categorías: Salud y prácticas espirituales/religiosas; Relaciones entre benzedura y prácticas de salud y cuidado. La benzedura se percibe como una alternativa en la determinación, la hospitalidad y la atención.

Descriptores: Atención primaria de salud; Espiritualidad; Humanización de la atención.

1. Acadêmica do Curso de Graduação em Enfermagem da Universidade Federal do Triângulo Mineiro (UFTM), Uberaba, MG, Brasil. ORCID: 0000-0003-3019-6393 E-mail: janamaia15@gmail.com

2. Cientista Social. Mestre e Doutora em Sociologia. Pós Doutora em Atenção à Saúde, Uberaba, MG, Brasil. ORCID: 0000-0001-6106-1200 E-mail: luassunc@gmail.com

3. Enfermeira. Mestre em Enfermagem Psiquiátrica. Doutora em Psiquiatria. Professora Associada do Programa de Pós Graduação Stricto Sensu em Atenção à Saúde da UFTM, Uberaba, MG, Brasil. ORCID: 0000-0002-1176-8643 E-mail: leiner.r.rodrigues@gmail.com 


\section{INTRODUÇÃO}

$\mathbf{R}$

ecentemente, a benzedura tem conseguido legitimação junto à municípios de alguns estados do Brasil, como é o caso do Paraná ${ }^{1}$. Considerando a abertura que vem sendo proporcionada às benzedeiras na parceria destas, e as políticas públicas voltadas para a sáude $^{1}$, é mister a busca por um maior detalhamento sobre os diferentes papéis assumidos por essas agentes junto aos usuários, bem como verificar a perspectiva dos profissionais de enfermagem sobre a atuação desta prática nas áreas atendidas pela Saúde da Família.

A participação da benzedura na saúde pode ser entendida como um recurso na busca por respostas e por tentativas de restauração da saúde física e mental. A despeito da importância do saber biomédico, ele não tem se mostrado competente no trato das questões que englobam a totalidade do ser humano².

0 presente estudo tem como objetivo caracterizar os profissionais de enfermagem e apresentar a sua perspectiva sobre a benzedura junto à Estratégia Saúde da Família em município mineiro.

\section{MÉTODO}

Trata-se de estudo descritivo, exploratório e quantiqualitativo realizado em um município do Triângulo Mineiro, Minas Gerais. A presente pesquisa integra estudo maior intitulado "A benzedura e o SUS: práticas espirituais/religiosas na saúde e percepções de trabalhadores, usuários e benzedores de áreas atendidas pela Estratégia Saúde da Família”.

Atualmente, segundo informações da Secretaria Municipal de Saúde de Uberaba (SMSU) ${ }^{3}$, há 51 equipes saúde da família que estão distribuídas em três distritos sanitários (DS) da zona urbana e na zona rural, contando com 87 profissionais de enfermagem. Foram excluídos profissionais de enfermagem em licença saúde. Incluíram-se profissionais que exerciam a função na unidade de saúde há, pelo menos, um ano.

Para esta pesquisa, foram coletados dados nos três distritos sanitários da zona urbana e na zona rural. Foram inquiridos 44 profissionais de enfermagem que, num primeiro momento, responderam ao questionário de caracterização sociodemográfica e de identificação das práticas de benzedura, e por sete profissionais de enfermagem (enfermeiros(as) ou técnicos(as) de enfermagem) de sete equipes saúde da família que, num segundo momento, concederam entrevistas, as quais permitiram explorar a perspectiva dos profissionais sobre a prática da benzedura. Estas foram definidas por meio de sorteio efetuado com utilização do Programa Excel@. A coleta de dados foi realizada no período de outubro de 2016 a janeiro de 2017. As variáveis referentes à caracterização dos informantes da ESF foram: sexo, cor, função, religião, uso da prática de benzedura.

Relativamente aos questionários, os dados coletados foram tabulados. Os resultados foram obtidos por meio de operações da estatística descritiva e apresentados em forma de tabelas.

Seguiu-se a proposta da saturação teórica ${ }^{4,5}$. Nessa perspectiva, a coleta de novas entrevistas foi suspensa quando os dados coletados se mostravam redundantes ou repetitivos. No que concerne às entrevistas, foi realizada a análise temática dos $\operatorname{dados}^{6}$, da qual foram identificadas categorias. Estas emergiram a partir do tratamento das informações quando da leitura e análise do material e, por isso, não foram definidas de modo apriorístico.

Este estudo foi aprovado por Comitê de Ética em Pesquisa da Universidade Federal do Triângulo Mineiro sob parecer $\mathrm{n}$ o 1.774 .886 . Para resguardar sua confidencialidade, os entrevistados foram identificados por letra seguida de número. A inserção dos participantes ocorreu após esclarecimentos quanto a proposta do estudo, bem como após a assinatura do Termo de Consentimento Livre e Esclarecido, seguindo-se os preceitos estabelecidos pela Resolução 466/12, de 12/12/2012, do Ministério da Saúde. 


\section{RESULTADOS}

Perfil sociodemográfico dos profissionais de enfermagem

Dos profissionais que responderam ao questionário, 90,9\% são pertencentes ao sexo feminino, $56,9 \%$ possui pele branca, seguida pela parda com $29,5 \%$, com maior participação de enfermeiros $(88,7 \%)$ no preenchimento dos questionários estruturados (Tabela 1).

Constatou-se que 43,1\% dos entrevistados estão vinculados a religião católica, seguidos da religião kardecista (27,3\%), e os demais com adesão a outras religiões (Tabela 1).

Tabela 1. Participantes segundo variáveis sociodemográficas. Uberaba, Minas Gerais, 2017.

\begin{tabular}{|c|c|c|c|}
\hline Variáveis & Sociodemográficas & Número & Percentual \% \\
\hline \multirow[t]{2}{*}{ Sexo } & Feminino & 40 & $90,9 \%$ \\
\hline & Masculino & 04 & $9,1 \%$ \\
\hline \multirow[t]{5}{*}{ Cor } & Branca & 25 & $56,9 \%$ \\
\hline & Preta & 03 & $5,8 \%$ \\
\hline & Amarela & 02 & $4,5 \%$ \\
\hline & Parda & 13 & $29,5 \%$ \\
\hline & Sem Declaração & 01 & $2,3 \%$ \\
\hline \multirow[t]{2}{*}{ Função } & Enfermeiro & 39 & $88,7 \%$ \\
\hline & Técnico de enfermagem & 05 & $11,3 \%$ \\
\hline \multirow[t]{10}{*}{ Religião } & Agnóstica & 01 & $2,3 \%$ \\
\hline & Candomblé & 01 & $2,3 \%$ \\
\hline & Católica & 19 & $43,1 \%$ \\
\hline & Evangélica & 03 & $6,8 \%$ \\
\hline & Islâmica & 01 & $2,3 \%$ \\
\hline & Kardecista & 12 & $27,3 \%$ \\
\hline & Kardecista e Umbanda & 02 & $4,5 \%$ \\
\hline & Umbanda & 01 & $2,3 \%$ \\
\hline & Não Informado & 01 & $2,3 \%$ \\
\hline & Sem religião & 03 & $6,8 \%$ \\
\hline Total & & 44 & $100,0 \%$ \\
\hline
\end{tabular}

Dos profissionais inquiridos, 68,2\% já utilizaram a benzedura (Tabela 2), sendo que destes a maior parte são católicos e kardecistas.

Tabela 2. Profissionais de acordo com a utilização da benzedura. Uberaba, Minas Gerais, 2017.

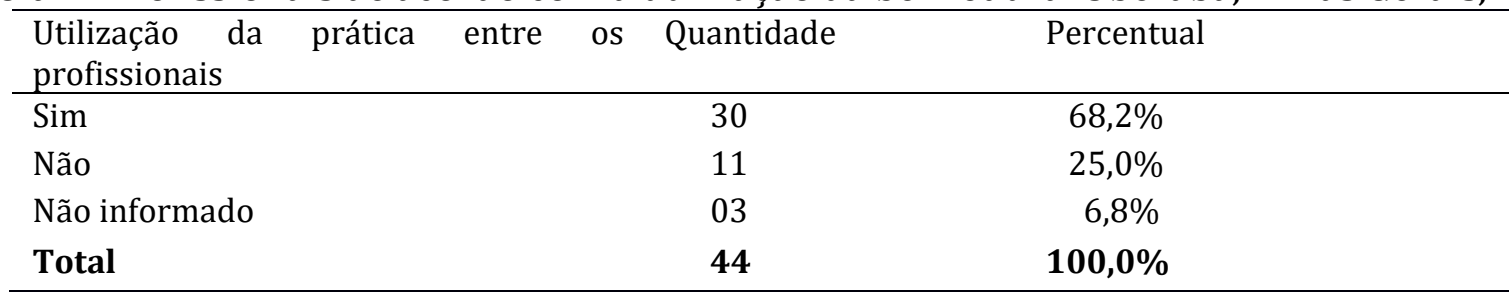

\section{Análise temática}

Para esta fase, participaram sete profissionais de enfermagem, sendo dois do DS I; dois atuantes no DS II, dois do DS III e um da zona rural.

A partir da análise do material coletado, despontaram duas categorias temáticas: "Saúde e práticas espirituais/religiosas" (I); "Relações entre benzedura e práticas de saúde e cuidado" (II), (Quadro 1).

A categoria "Saúde e práticas espirituais/religiosas" possui duas subcategorias: "Dilemas da interface entre saúde e práticas espirituais/religiosas" (1); "Benefícios da interface entre saúde e práticas espirituais/religiosas" (2), (Quadro 1). Da categoria "Relações entre benzedura e práticas de saúde e cuidado" surgiram as subcategorias: "Oposição" (3); "Aproximação" (4), (Quadro 1). 
Quadro 1. Categorias temáticas e subcategorias acerca do uso da benzedura por profissionais de enfermagem. Uberaba, Minas Gerais, 2017.

\begin{tabular}{|l|c|}
\hline CATEGORIA TEMÁTICA & SUBCATEGORIA \\
\hline $\begin{array}{l}\text { I. Saúde e práticas } \\
\text { espirituais/religiosas }\end{array}$ & 1. Dilemas da interface entre saúde e práticas espirituais/religiosas \\
\cline { 2 - 3 } $\begin{array}{l}\text { II. Relaçóes entre benzedura e e } \\
\text { práticas de saúde e cuidado }\end{array}$ & 2. Benefícios da interface entre saúde e práticas espirituais/religiosas \\
\cline { 2 - 2 } & 1. Oposição \\
\hline
\end{tabular}

\section{Saúde e práticas espirituais/religiosas}

\section{Dilemas da interface entre Saúde e práticas espirituais/religiosas}

De acordo com os depoentes, há uma deficiência acerca da formação em práticas espirituais/religiosas e essa carência dificulta o trabalho e a intervenção da equipe junto à comunidade. Após obterem os dados sobre as práticas espirituais/religiosas, por meio do mapeamento na área de atuação, não sabem como agir. Salientam, assim, a necessidade deste treinamento entre os profissionais:

Não temos formação para lidar com questões espirituais/religiosas trazidas pelos pacientes. Foi o que eu falei: tem que ser uma coisa que venha pra área da saúde porque eu acho que tem muitas dúvidas/dificuldades e tem que ser uma coisa trabalhada/discutida/compartilhada. Eu acho que as pessoas não têm conhecimento (E5).

Apesar de você fazer o levantamento: tantas benzedeiras, já passa pra outro tópico. Então eu acho que necessitava mais aprofundamento. Não temos capacidade de acolher as demandas espirituais/religiosas dos usuários. Falta, eu acho, informação/treinamento. Principalmente nessa área onde a gente nem discute em equipe (E2).

Aponta-se que a equipe não estabelece comunicação sobre os aspectos espirituais/religiosos que se manifestam na área de atuação, indicando que tal assunto não é compartilhado entre os profissionais. Não há formação ou preparo para tratar de assuntos que envolvam religiosidade (E2; E4; E6). Durante a formação acadêmica o foco está no fisiopatológico. As questões culturais, sociais e religiosas são pouco ou quase nunca abordadas. Assim, para tratar desses assuntos, os profissionais usam de conhecimentos e opiniões pessoais:

A não ser a Dra... que gostava e até recomendava, os outros eu não vejo nenhum comentário deles falarem alguma coisa. Nem todos percebem questões relacionadas a espiritualidade/religiosidade. Aqui é raridade aqueles que tem uma religião. Que falam sobre o assunto (E3).

Há pouca comunicação entre o conhecimento médico e o saber espiritual. Até tem, mas muito pouco. É pouco difundido. Na minha formação acadêmica não teve aspectos espirituais/religiosos. Ninguém falava nada disso lá. Pelo menos pra dar uma pincelada ou pelo menos para o profissional respeitar. Ele não acredita naquilo nem nada, ele não vai difundir, não quer falar nada sobre aquilo, mas ele tem que respeitar pelo menos. Ter uma vivência pra poder respeitar (E6).

Falta, eu acho, informação/treinamento. Principalmente nessa área onde a gente nem discute em equipe. Apesar de você fazer o levantamento: tantas benzedeiras, já passa pra outro tópico. Então eu acho que necessitava mais aprofundamento. Eu acho que deveria ser mais praticado/discutido entre a equipe, ter mais capacitações nesse sentido, mais orientações (E2).

Não tem muito formação, de um treinamento/ capacitação, alguma coisa assim de um poder científico que fala que pode ser enquadrado e que tem fundamento. Eu nunca, na faculdade/curso, tive nada sobre essas práticas. E às vezes o que tem de conhecimento sobre religiosidade vêm da criação. Dos antigos, de alguém da família que acreditava e passa pra gente. Vêm de gerações, eu acho (E4).

Devido à formação com foco no biológico, os profissionais não comentam e acham irrelevante discutir pautas relacionadas à práticas espirituais/religiosas, de modo a não se posicionarem sobre o assunto:

Geralmente os profissionais de saúde não se posicionam sobre aspectos relacionados a religiosidade/ espiritualidade (E5).

Ademais, práticas espirituais/religiosas podem conduzir ao abandono dos medicamentos, à confiabilidade extrema nos líderes religiosos, ao sectarismo limitante. Assim, recomenda-se que a religiosidade seja sem exageros, caso contrário pode prejudicar.

Eu acho que algumas religiões, às vezes, podem sim influenciar no sentido de suspender medicação (E1).

Porque também vi pessoas de algumas religiões que não podem tratar, no caso deixam o tratamento medicamentoso, pra fazer só o que Deus, a igreja acreditam estão falando. Aí acho que já se torna prejudicial. A religião acho que 
ajuda ou também pode, às vezes, prejudicar. Depende da pessoa, do fanatismo. Tem que ser tudo ponderado. Nada em excesso (E5).

Pessoa bitolada, você vê umas religiões muito fechadas/conservadoras você vê que aquilo está limitando a pessoa financeiramente e outras coisas. Socialmente também. Eu acho que algumas limitam muito socialmente. Aquilo causa um sofrimento pra pessoa (E6).

\section{Benefícios da interface entre Saúde e Práticas espirituais/religiosas}

De um lado, apontou-se que práticas espirituais/religiosas podem trazer cura inexplicável, proporcionar sensação de alívio, ajudar na autoestima, no pensamento positivo (E1), no fortalecimento (E1), melhorando o processo de saúde e doença:

É igual eu falei a questão da fé. Eu já vivenciei, porque tenho alguns anos de enfermagem, casos que você fica se perguntando como, por quê. Então, às vezes tem um tumor/doença muito grave e está marcada uma cirurgia e ela procura a religião dela e foi constatado, mesmo, com exames, que aquilo sumiu. Em pouco tempo (E2).

Tem médico que fala: "Essa paciente aqui não tem nada, o problema dela é mais espiritual". Não sei, às vezes um benzedor ou uma religião ali entrando na maioria das vezes funciona (E3).

Ajudaria bastante associar saúde e religiosidade. Eu até brinco com as meninas porque aqui tem tudo quanto é tipo de religião e então tem hora que vem algumas pessoas que você vê que a pessoa está carregada de alguma coisa que eu não sei explicar. A pessoa não está bem. Esse daí está precisando de uma religião (E6).

Eu acho que a religiosidade pode ajudar na autoestima, a pessoa a encontrar um caminho às vezes e isso vai ajudar em tudo (E1).

Eu acho que é a fé, mesmo. Se a pessoa acredita que aquilo vai melhorar pra ela, se a pessoa acreditar pode ajudar no processo de saúde e doença (E5).

As mudanças de comportamento resultantes da frequência a uma religião podem impactar significativamente na saúde do indivíduo. Exemplos disso são: a caminhada até a igreja; o lazer proporcionado; o envolvimento social relacionado às práticas que realizam em prol da comunidade religiosa. Essas são contribuições na mudança de comportamento que, por sua vez, incidem positivamente no processo de desmedicalização:

Geralmente é questão de mudança de hábito. Mudar hábitos alimentares, praticar uma atividade física, um lazer, frequentar uma religião, tudo isso vai trazer um bem-estar pra pessoa e melhorar a qualidade de vida dela (E5).

Um trabalho voluntário, uma religião, acredito que vai melhorar a depressão, os remédios e melhorando a autoestima também vai melhorar tudo e vai diminuir a medicação (E1).

Os enfermeiros relataram que a benzedura contribui no processo de desmedicalização pelo fato de ter ervas naturais que auxiliam, afirma-se que, dependendo da enfermidade, pode ajudar bastante. No entanto, alerta-se para o fato de que em determinadas enfermidades a utilização exclusiva desses meios pode ser prejudicial ao usuário:

Então a fé, sei lá.. Tem ervas, medicina natural que ajuda (E3). Eu penso assim... Benzeção ou remédio caseiro não tem uma coisa comprovada que vá funcionar, que vai resolver mesmo. Alguns casos a benzeção pode ajudar, mas não são todos. A gente sempre tem que orientar a não deixar o cuidado médico (E3).

Eu acho que quando se tem fé, uma crença, eu acho que às vezes não é só passar pelo médico também. Eu acho que tem outros meios também da gente acreditar em uma erva e outras alternativas. Eu acho que às vezes você está tentando um tratamento e não está dando certo, de repente é outro meio que funciona. Outra opção, mesmo (E4).

Foram destacados a hospitalidade e o respeito aos aspectos espirituais/religiosos dos usuários por parte dos profissionais, os quais acolhem o usuário para que o mesmo não abandone o seu tratamento, trazem ele para junto da equipe orientando-o e indagando-o sobre os tratamentos alternativos que utiliza, de modo a ouvi-lo atentamente, jamais se opondo aos seus valores religiosos e sempre o orientando. É necessário saber como agir na ocasião de surgimento deste tipo de demanda, atendendo igualmente a todos e dispensando as orientações necessárias, colocando em prática o respeito pela diversidade religiosa da comunidade atendida:

Eu acho que é trazer sempre o paciente pra perto da gente pra gente estar orientando e avaliando. Por mais que às vezes ela acredita, que ela tem fé, que vai ser bom, mas eu sempre oriento a não abandonar a gente aqui também (E4).

A gente abraça tudo. Chega drogado aqui, conversa, a gente atende, seja prostituta, homossexual. A gente abrange e abraça todos sem problema nenhum. Escuta todos. Independente de você ser espírita/católico. A pessoa sentou e conversou eu vou acudir o jeito que ela é. Se ela for espírita naquela hora eu vou ser espírita; se ela for crente, eu vou ser crente. É o jeito que a pessoa chegar (E7). 
São profissionais de saúde. Eles estão atuantes. Então, se eles não atenderem legal, não vai adiantar nada. Eles têm que fazer a parte deles, indiferente da pessoa, de onde ela seja (E6).

Eu acho que tem que respeitar cada religião. A gente respeita. Eu acho que um ser humano tem que respeitar o outro em todos os sentidos. Principalmente nesse, da religião. Cada um segue aquilo que acha que é bom pra ele. E a gente não pode intervir nisso, não. E respeitar a crença da pessoa. A gente faz todas as orientações, respeitando o indivíduo (E2).

Como a gente trabalha na estratégia da família, faz visita, vai nas casas e então encontra várias religiões e então o atendimento é normal pra todos. Não tem diferença (E1).

\section{Relações entre benzedura e práticas de saúde e cuidado Oposição}

A oposição entre o saber religioso e o saber médico foi bem demarcada nas falas dos enfermeiros com suas posições de 1) intervenção sobre as práticas que não apresentam legitimidade perante o saber biomédico e de 2) orientação ao não abandono do tratamento médico e das medicações. Ambos os posicionamentos ilustram a imposição do modelo biomédico sobre outras práticas de saúde e cuidado.

Acredita-se que a benzedura, em si, não traga riscos ao usuário, porém o uso de ervas pode trazer complicações. Desse modo, é necessário avaliar e orientar sobre os "riscos e benefícios" dessa utilização:

Falamos dessa maneira: "Pode ir lá, usar". Aí a gente tem que avaliar também o que é que essa pessoa recomendou e está usando. De repente é uma coisa que a gente vê que não está certo, não vai fazer bem, não vai ajudar no tratamento, aí o papel é orientar aquela pessoa dos riscos e benefícios (E2).

Ele usava barbatimão e benzia. Só que piorava. Ele fazia esse chá e banhava a ferida com aquela planta e ela piorava. Eu sempre oriento. No caso benzer não tem nenhum problema. O problema é quando usa alguma erva/planta e se aquilo está prejudicando (E5).

Com relação ao uso de ervas, a benzedura é colocada numa posição de inferioridade e submissão à ciência médica. Isso ocorre em função da falta de aprovação pela comunidade científica que desconsidera uma real eficácia dessa prática frente à doença do usuário.

Ao terem conhecimento do uso de práticas de benzedura, os profissionais orientam os usuários quanto à necessidade do uso concomitante ou da suspensão, caso haja interações ou reações adversas pelo uso de ervas, chás e banhos. A procura pelo médico é colocada sempre em primeiro plano. Nessa direção, o uso da benzedura não traz perigo à saúde do usuário desde que o mesmo faça o acompanhamento médico para amenizar os agravos e que não abandone o medicamento:

Às vezes tem remédio caseiro que você sabe que funciona, mas não pode ficar só naquilo. E o que eu falo: quer usar, quer fazer, faça! Mas que não fique só naquilo. Porque tem gente que bebe um chá que é bom pra pressão, ele só toma o chá, não toma o remédio pra pressão. Eu sempre oriento assim: no caso, usa os dois, mas sempre o tratamento médico tem que permanecer. A gente sempre tem que orientar o tratamento médico, não deixar o cuidado médico (E3).

As duas coisas, uma aliada à outra, que às vezes uma coisa ela acredita e a outra ela quer deixar de tomar os remédios, mas eu falo, sempre oriento a não abandonar. Fica com os dois. Então eu falo: "Nunca abandona o tratamento médico pra outras práticas" (E4).

Eu falo que eles podem estar indo benzer mas que tem que fazer o tratamento médico. Aí, às vezes, quando estão usando algumas ervas, pede pra evitar. Agora, se ver que está melhorando, não está prejudicando aquela lesão. (E5). Fazendo o tratamento certinho e fazendo a benzeção, o que não pode é estar deixando o tratamento medicamentoso (E1).

Quando se abordou os enfermeiros sobre uma possível parceria com os benzedores, os mesmos relataram que há discriminação por parte dos profissionais de saúde, o que dificultaria essa atuação conjunta, gerando uma resistência em trabalhar e dialogar sobre essas práticas: Tem muitos profissionais que acham que é balela, que não acreditam. Tem profissionais que não têm a mente tão aberta (E4).

Seria importante trazer esse assunto pra equipe de saúde da família. Talvez uma discussão, talvez trazer na reunião de Conselho porque muita gente não conhece e tem muita que tem preconceito (E5).

Não acreditam muito, não. Não levam muito a sério. Os profissionais, em geral, que a gente conversa, não acreditam muito nesse fato de benzedeira, não. Tem uma certa resistência quanto à prática (E2).

Os entrevistados pontuaram que há oposição entre os saberes religioso e médico. Isso ocorreria em função da: descrença desses profissionais; vergonha em assumir uma crença 
perante os colegas; visão reducionista de que apenas o conhecimento científico é valido. Embora não ocorra a comunicação entre esses saberes:

Por mais que ele acredite também, mas o outro não acredita, ele não vai abrir, vai ter vergonha também de poder assumir que aceita/concorda (E7).

Muitos profissionais não acreditam. Eles estudaram pra aquilo ali, pra aquela formação/tratamento ali e acham que é só aquilo ali (E4).

Os médicos não acreditam muito. De um modo geral (E1).

\section{Aproximação}

Acredita-se estar havendo uma mudança nos atendimentos atualmente, nos quais os profissionais são mais receptivos a outras práticas terapêuticas e à aproximação com estas. Aponta-se que, embora os profissionais não dialoguem sobre religião com os usuários, é de extrema importância em um país laico e com forte diversidade religiosa como o Brasil, que se insira na pauta de discussão da equipe, visto que esse tema não foi exposto na academia. Ressaltam a importância de parceria com a benzedeira. Considerando a real possibilidade de o usuário não deixar de frequentá-la, essa parceria visaria orientá-lo e à benzedeira sobre os cuidados necessários e quanto aos possíveis riscos quando do uso de práticas não testadas e não reconhecidas cientificamente:

Aqui os médicos sempre foram muito... hoje em dia eles estão mais abertos a outros saberes. (E3).

Não sei se na sua formação acadêmica você teve isso [formação em religiosidade/espiritualidade]. Na minha não teve. (E6).

Eu acho que seria importante a parceria a té mesmo pra aumentar esse número de pessoas, que hoje em dia está muito pouco. De benzedeiras. Eu acho que nesse ponto de regulamentar a benzeção até seria importante nesse sentido das benzedeiras terem essa orientação, saber o entendimento (E2).

Há vários posicionamentos favoráveis à benzedura. Os informantes percebem que na busca da benzedura existem fatores diversificados: desde a tentativa de resolução de problemas para os quais não há meios de intervenção eficazes, como por exemplo doenças graves até a hospitalidade/atenção que o usuário muitas vezes não encontra no atendimento hospitalar. Ela é buscada para ajudar a melhorar e é tida então como uma força maior na resolução de questões que fogem à racionalidade e à qualificação científica:

Na maioria das vezes procura o benzedor por algum motivo de doença. Mais doença física (E6).

Se a pessoa acredita que a benzeção vai ajudar a melhorar, ela faz, é cultural (E5).

Eu acredito que é buscando uma força maior pra cada problema, cada situação (E3).

As falas dos enfermeiros explicitam que a benzedura tem um papel fundamental no processo saúde/doença, pois proporciona força para o usuário, uma autoajuda, um amparo em meio às intempéries da vida, assim como boas energias e bons fluidos. Porém, para a benzedura ter efeito é necessário que seja realizada com caridade e humildade por parte do benzedor. Os usuários dão credibilidade aos benzedores que assim realizam seu trabalho:

Então, se ele acredita que aquilo ali vai tratar/curar/ajudar, eu acho que é um papel de ajuda, mesmo. De autoajuda, ajuda própria, da própria pessoa. Eu acredito muito em benzeções quando você faz ali por caridade. Não aquelas benzeções que às vezes a pessoa cobra. Essas eu já não tenho tanta credibilidade. Mas quando você vê que a pessoa é humilde/simples/boa, que faz por caridade mesmo, aí eu boto fé (E2).

Eu acho que a gente vai muito ali nos bons fluidos. Eu acredito, acho que vai dar certo, que vai ser bom, me dá energia boa (E4).

Os relatos mostram que os atendimentos realizados pelos profissionais de saúde são destituídos de atenção e hospitalidade, eles mecanizam o atendimento para evitar envolvimento com o usuário e para realizar um rápido atendimento. Ao contrário, é necessário investigar mais a história do paciente e ouvi-lo:

Acho que o médico, hoje, a maioria não escuta o paciente. Ele acha que está certo e que o paciente não tem razão. $O$ médico sabe e o paciente não tem opinião (E1).

Então, ele não quer nem saber a história do paciente, ele quer ficar livre dele. Eu acho que depende muito até mesmo do ouvir, de pesquisar mais pra chegar no diagnóstico. Às vezes até o ouvir é mais importante do que a medicação (E4).

Eu conheço outros médicos porque eu já trabalhei em UPA, em outra unidade de saúde. Eu estou te falando em geral: eles vão atender, vão perguntar qual a dor do paciente, onde é a dor, vão tratar aquilo ali e não vão perguntar com 
quem ele mora, quem é a família dele, quem é o parente/vizinho, se ele tem cachorro, se não tem. Eles não querem saber de nada daquilo (E6).

Da fala dos enfermeiros, vez ou outra, emana o efeito da fé na vida das pessoas. A crença/fé em algo que lhe fará bem e/ou se sentir melhor, ajuda o usuário no processo saúde/doença.

Eu tenho uma pomada que é corticoide. E o paciente estava com uma ferida. Para o ferimento dele não faz sentido nenhum eu passar essa pomada. Passa a pomada, então, mas não adianta pra nada. Fala pra ele que é bom, se ele acreditar que é bom, vai dar certo. Se a pessoa acreditar naquilo, vai funcionar. Se a pessoa acredita naquilo ali vai dar certo (E6).

No caso da benzedura, além de fortalecimento, ela fornece respostas plausíveis a questões que surgem na vida das pessoas desde tenra idade:

Eu fui criada, quando era pequena, na benzeção. A minha mãe levava (E2).

Eu tenho muita fé/crença. Acredito que tem muita coisa que nos influencia também. Eu lembro da minha mãe medir meu irmão pequeninho que ele estava com vento virado e realmente o jeito que ela media dava uma diferença (E4).

0 posicionamento favorável desponta, igualmente, na questão da resolutividade. $\mathrm{Na}$ perspectiva dos depoentes, os usuários às vezes procuram uma forma alternativa de tratamento por crerem que é mais efetivo que a medicina, por não conseguirem consultar com um especialista. De um modo ou de outro, percebe-se que a demanda é por solução eficaz para a enfermidade:

Às vezes procura primeiro outros meios, até procurar um médico. Tem gente que acredita, mais, às vezes, em uma benzeção, do que no médico mesmo (E2).

No caso da saúde, tem médico que às vezes não consegue, vai no benzedor toma uma garrafada e a pessoa tá bem. Um monte de gente aqui relata isso (E3).

Uma paciente aqui da rua que é da igreja evangélica e o pastor falou que Deus ia curar. Ela deixou de fazer/tomar as medicações - ela é diabética e hipertensa - a ouvir uma opinião da agente comunitária/médico (E5).

Porque os usuários contam e a gente vê porque eles chegam aqui pra consultar, estão com alergia: "É só uma alergia, passa tal coisa". Eles nem chegam a comprar o medicamento, ela vai na benzedeira, dá umas três, quatro benzeções lá e já sara (E7).

Eu acho que até pela dificuldade de conseguir uma consulta/especialista/medicação ela torne, também, pra esse lado (E4).

0 posicionamento favorável à benzedura surge mediante a questão do tratamento integral. A necessidade de perceber os sujeitos na sua totalidade emerge no depoimentos, que expõe a importância de tratar o indivíduo de maneira holística, para assim proporcionar um "processo de saúde melhor":

É um conjunto e as pessoas têm muito essa cultura só de medicamento. Só o remédio que vai resolver. E eu acho que é melhorar no todo a pessoa. Porque a partir do momento que você melhora você tem um processo de saúde melhor porque você a está vendo holisticamente, no todo. De um modo geral (E5).

Ao longo da entrevista os profissionais pontuaram a importância da parceria com os benzedores para a recepção hospitaleira do público, a proximidade com a comunidade e a diminuição do consumo de medicamentos. A benzedura, nesse sentido, é um artifício específico da comunidade que auxilia a população em momentos difíceis:

Em se tratando de comunidade daí eu acho que é válido porque você aqui dentro não consegue algo com o paciente $e$, às vezes, a comunidade pode conseguir algo que você como profissional não...então eu acho que num programa como o Saúde da família que tem que ser em equipe, tanto o postinho como a comunidade (E3)

Às vezes um carinho ali, um afeto ou mesmo vamos supor a benzeção vai ser mais positivo do que a própria medicação (E4).

Ele está com aquela dor: "Acho que eu preciso me benzer. Estou com essa dor". Ele vai lá, benze e não tomou a medicação (E6).

\section{DISCUSSÃO}

0 fato de haver mais enfermeiros respondendo aos questionários explica-se pelo contexto de aplicação do instrumental, onde estes profissionais tomavam frente aos técnicos de enfermagem e aos agentes comunitários de saúde (ACS) que, por sua vez, se sentiam mais confortáveis em repassar o questionário para o enfermeiro. Ao que tudo indica, tal situação se concretizava por uma questão de respeito à escala de poder dentro da unidade de saúde, caracterizando uma hierarquização no contexto da enfermagem ${ }^{8}$. 
Assim como nesta pesquisa, que identificou a predominância de católicos, acompanhados de kardecistas, tem-se verificado em outros estudos que a religião católica ainda detém a maior parte das adesões seguida da religião kardecista ${ }^{9-11}$. A despeito de tal prevalência, é possível perceber que outras religiões se fazem presentes, confirmando a diversidade religiosa brasileira ${ }^{12}$.

A incidência maior de profissionais católicos e kardecistas, entre aqueles que utilizaram a benzedura, pode ser um reflexo das próprias crenças professadas pelos benzedores e benzedeiras. Os ritos da benzedura misturam conhecimento popular e religiosidade ${ }^{13}$. Muitas benzedeiras se declaram católicas, porém recebem fortes influências de religiões afrobrasileiras e de rituais indígenas ${ }^{13}$.

A deficiência em relação ao treinamento e capacitação sobre práticas espirituais/religiosas indica a extrema importância de implementação dessa temática no ensino de enfermagem ${ }^{14}$.

O não estabelecimento de comunicação entre os profissionais da equipe de enfermagem, associada à sua falta de formação para tratar da temática relacionada à espiritualidade/religiosidade, são evidenciados. Uma pesquisa apontou que os profissionais não abordam espiritualidade/religiosidade no ambiente de trabalho em razão dos cursos de graduação nas universidades não os terem preparado, tratando essa temática como opcional ${ }^{15}$. Noutro estudo com enfermeiros, estes relataram não possuir conhecimento suficiente para realizar uma abordagem sobre espiritualidade/religiosidade; tal fato ocorre devido à pouca ênfase dispensada a essa temática nos cursos de graduação, que negligenciam essa necessidade ${ }^{14}$.

As pautas vinculadas aos aspectos espirituais/religiosos são tidas como irrelevantes. Embora haja a busca por um modelo mais focado na promoção da saúde, a realidade do serviços de saúde ainda é influenciada pelo paradigma do modelo biomédico clínico tradicional focado na doença ${ }^{16}$. Atualmente, porém, essa realidade tem tomado outro rumo ${ }^{17}$. No Brasil, várias faculdades têm, de um lado, introduzido o estudo sobre espiritualidade na grade curricular e, de outro lado, têm aberto centros de atendimento e pesquisa voltados para a questão da espiritualidade ${ }^{17}$.

O sectarismo religioso e suas implicações na saúde são apontados em relação ao apego exagerado a uma prática religiosa e ao abandono do tratamento médico. A religiosidade traz alívio ao usuário, proporcionando sensação de conforto e ajudando na saúde geral, porém o fanatismo religioso pode afetar a saúde do indivíduo ${ }^{15,18,19}$.

Questões como alívio, autoestima, pensamento positivo, fortalecimento emergem no contexto de interface entre saúde e práticas espirituais/religiosas. Estas proporcionam o enrobustecimento do sujeito para encarar o processo de adoecimento, além de contribuírem significativamente na terapêutica ${ }^{18,19}$.

São identificadas mudanças de comportamento relacionadas ao vínculo religioso. A partir do momento em que o sujeito utiliza terapias populares/religiosas, o mesmo passa a seguir orientações que mudam sua rotina, como dietas especiais, formas de sentir e de pensar que facilitam a cura, além de oferendas de preces e alimentos, ou doações materiais às divindades que proporcionam o restabelecimento do usuário ${ }^{20}$.

A contribuição da benzedura no processo de desmedicalização é um fato importante. Estudo realizado com 30 profissionais em seis Unidades da Estratégia Saúde da Família do município do Rio Grande/RS demonstrou que a utilização de plantas medicinais é uma forte opção terapêutica de cuidado, tendo em vista que seu uso advém de saberes antigos e contribui para a desmedicalização. 0 maior passo para implementação desse saber nas unidades de serviço em saúde convencionais é o preparo e capacitação dos profissionais deste serviço ${ }^{21}$.

A hospitalidade e o respeito aos aspectos religiosos/espirituais aparecem como questões fundamentais. Em pesquisa realizada com médicos da saúde da família e da comunidade de diferentes nacionalidades constatou-se que a abordagem da espiritualidade no 
atendimento proporciona a criação e o fortalecimento do vínculo entre o médico e o usuário. Assim, no caso de um usuário bem orientado, práticas espirituais podem colaborar na terapêutica trazendo benefícios ${ }^{22}$. Nessa direção, o profissional que demonstrar respeito e sensibilização pela espiritualidade do usuário construirá uma relação de confiança e conseguirá sua maior adesão aos cuidados propostos pelo profissional ${ }^{15}$.

A oposição entre o saber religioso e o saber biomédico é evidenciada mediante a exigência dos profissionais de enfermagem quanto à orientação sobre riscos e benefícios do uso de ervas. Tal atitude aponta para uma necessária intervenção sobre o emprego de outras práticas de saúde e cuidado que não aquela respaldada pelo poder biomédico. Trabalho feito com enfermeiros em Crato/CE evidenciou que a conduta de respeitabilidade às crenças dos sujeitos deve ser adotada no início do trabalho com a comunidade. Simultaneamente, é necessário haver educação em saúde junto a essas práticas populares, as quais podem trazer consequências aos usuários 23 .

A oposição se mostra como realidade a partir do momento em que a busca pelo profissional de saúde é colocada em primeiro plano. Estudo realizado com dez benzedeiras nas cidades do interior de São Paulo e Minas Gerais apontam que a submissão de práticas de cura não oficiais ao modelo biomédico se dá devido à modernização e ao avanço da ciência e um sistema formal de saúde que acaba negligenciando os sistemas populares de cuidado ${ }^{24}$.

A resistência dos profissionais de saúde em estabelecer parceria com benzedores teria vínculo com a sua formação reducionista, fragmentada e biologicista. A falta de comunicação entre os profissionais conduz à assistência fragmentada e à permanência de pré-noções frente a práticas espirituais/religiosas, restringindo-as unicamente aos líderes religiosos ${ }^{15}$.

0 receio de discorrer sobre práticas espirituais/religiosas com o usuário indica a necessidade de treinamento para uma abordagem mais efetiva que diminua o risco de dupla interpretação do usuário e de discriminação por parte dos profissionais ${ }^{15}$.

A aproximação entre o saber religioso e o saber médico é vista como uma possibilidade. A validação e o resgate dos saberes populares (uso de ervas, chás, benzeção, e outras) possibilita uma reconciliação entre profissionais de saúde e pessoas que dominam o saber desta cultura. Ademais, esses recursos podem ser compreendidos como medida de autocuidado e de autonomia dos usuários que muitas vezes são marginalizados ${ }^{25}$.

A procura pela benzedura está pautada em motivos diversificados. Os benzedores são buscados para resolução de problemas financeiros, matrimoniais, de saúde e espirituais ${ }^{24}$.

A benzedura é caracterizada por sua relação com a caridade e a humildade. A doação/caridade presente no ofício de benzedores se embasa em valores humanísticos que trazem efetividade ao tratamento. Mediante serviços prestados, eles recebem reconhecimento e status frente a comunidade 26

Percebe-se a falta de envolvimento e de atenção do profissional para com o usuário. A maior parte dos atendimentos feitos por benzedeiras em suas casas e em contato direto com o usuário revela-se como uma comunicação de fácil compreensão, que traz conforto e sensação de acolhida. Geralmente ocorre o inverso nos atendimentos em práticas oficiais de saúde, onde há o distanciamento e a ausência de comunicação legível e compreensível, o que leva o usuário a buscar meios que ofereçam aquele amparo ${ }^{26}$.

Os efeitos da fé na vida dos sujeitos também é destacado. Estudo realizado com equipe de cuidados oncológicos paliativos no Sul do Brasil demonstrou que, por meio da espiritualidade, é possível oferecer conforto, bem como o fortalecimento do pensamento positivo, trazendo resultados benéficos ao usuário ${ }^{27}$.

Aponta-se para a plausibilidade relacionada à benzedura. A religiosidade e os terapeutas populares possuem um significado importante dentro do processo saúde-doença-cuidado, pois em alguns casos oferecem respostas a questões que são inexplicáveis ao modelo biomédico 28 .

A resolutividade associada à benzedura é outra questão que emerge. Dentre os participantes de um estudo feito em Goiânia-GO, constatou-se que a maioria dos usuários de 
práticas populares acredita na sua eficácia e faz uso delas para solucionar problemas de saúde, buscando-as antes mesmo do médico ou do serviço de saúde. As práticas religiosas envolvem uma acolhida que ajuda o usuário e sua família a contornar experiências de sofrimento, ultrapassando as soluções oferecidas pelo sistema de saúde formal ${ }^{28}$.

A integralidade é um aspecto aliado à benzedura. Pesquisa realizada na cidade de Caraúbas/RN revela que a prática profissional deve reconhecer que o indivíduo vai além de aspectos fisiológicos, abrangendo dimensões biopsicossociais e espirituais para, dessa maneira, ampliar e aprimorar as modalidades terapêuticas que melhor atendem às necessidades do usuário ${ }^{26}$.

Existe uma tendência ao tratamento pouco receptivo e à excessiva medicalização. Tais fatos podem ocorrer em função das demandas que chegam ao serviço fugirem da rotina e organização do seu trabalho ${ }^{29}$. Partindo desse pressuposto, o benzedor que está inserido na realidade dos usuários facilita a busca de outra abordagem que não a medicamentosa.

\section{CONCLUSÃo}

A análise dos dados sociodemográficos revelou um perfil de profissional de enfermagem que já vem se constituindo historicamente: do sexo feminino e de cor branca. Evidenciou igualmente a predominância de profissionais adeptos do catolicismo e do kardecismo, que mais fizeram uso da benzedura.

Percebeu-se resistência à benzedura devido à formação reducionista/biologicista que despreza as questões culturais, sociais e religiosas. A despeito disso, ela é percebida enquanto prática voltada tanto para resolutividade quanto para a hospitalidade/atenção, muitas vezes desconsiderados nos serviços de saúde.

Este estudo teve como limitação a quantidade reduzida de enfermeiros entrevistados. Tal fato se deveu à impossibilidade de dar continuidade ao contato inicialmente estabelecido com os profissionais de enfermagem que haviam preenchido o questionário estruturado, devido ao contexto de exoneração por término de contrato e a substituição por profissionais concursados, levado a cabo pela prefeitura do município.

\section{REFERÊNCIAS}

1. Ducati A, Dionísio B. Benzedeiras são consideradas profissionais da saúde no Paraná. Jornal Globo-G1 [Internet], 11 maio 2012 [citado em 26 jan 2017]. Disponível em: http://g1.globo.com/pr/parana/noticia/2012/05/benzedeiras-sao-consideradas-profissionaisda-saude-no-parana.html

2. Melo SCC, Santana RG, Santos DC, Alvim NAT. Práticas complementares de saúde e os desafios de sua aplicabilidade no hospital: visão de enfermeiros. Rev Bras Enferm. [Internet]. 2013 [citado em 30 jan 2018]; 66(6):840-6. Disponível em: http://www.scielo.br/pdf/reben/v66n6/05.pdf. DOI: http://dx.doi.org/10.1590/S0034-71672013000600005

3. Prefeitura Municipal de Uberaba. Secretaria Municipal de Saúde. Plano Municipal de Saúde 20182021. Uberaba, MG: PMU; 2017. Disponível em:

http://www.uberaba.mg.gov.br/portal/acervo//saude/arquivos/2017/Plano\%20Municipal\%20 de\%20Saude\%202018-2021\%20aprovado\%20pelo\%20CMS.pdf

4. Glaser BG, Strauss AL. The discovery of grounded theory: strategies for qualitative research. New York: Aldine de Gruyter; 1967.

5. Fontanella BJB, Ricas J, Turato ER. Amostragem por saturação em pesquisas qualitativas em saúde: contribuições teóricas. Cad Saúde Pública [Internet]. 2008 [citado em 18 set 2018]; 24(1):17-27. Disponível em: http://www.scielo.br/pdf/csp/v24n1/02.pdf DOI: http://dx.doi.org/10.1590/S0102-311X2008000100003

6. Minayo MCS. O desafio do conhecimento: pesquisa qualitativa em saúde. 14ed. São Paulo: Hucitec; 2017.

7. Conselho Nacional de Saúde (Brasil). Resolução no 466, de 12 de dezembro de 2012. Aprova diretrizes e normas regulamentadoras de pesquisa envolvendo seres humanos [Internet]. Brasília, 
DF: CNS; 2012 [citado em 27 ago 2017]. Disponível em: http://bvsms.saude.gov.br/bvs/saudelegis/cns/2013/res0466_12_12_2012.html

8. Rodrigues AL, Barrichello A, Morin EM. Os sentidos do trabalho para profissionais de enfermagem: um estudo multimétodos. Rev Adm Emp. [Internet]. 2016 [citado em 05 fev 2018]; 56(2):192-208. Disponível em: http://www.redalyc.org/articulo.oa?id=155144607005

9. Instituto Brasileiro de Geografia e Estatística. Censo Demográfico, 2010: características gerais da população, religião e pessoas com deficiência [Internet]. Rio de Janeiro: IBGE; 2012 [citado em 03 nov 2017]. p. 89-105. Disponível https://biblioteca.ibge.gov.br/visualizacao/periodicos/94/cd_2010_religiao_deficiencia.pdf

10. Lima SRR. Kardec, magos negros, caboclos e preto-velhos: o espiritismo de Robson Pinheiro dos Santos [Internet]. [dissertação]. Juiz de Fora, MG: Universidade Federal de Juiz de Fora, 2016 [citado em 10 nov 2017]. Disponível em: https://repositorio.ufjf.br/jspui/bitstream/ufjf/5622/1/silasrobertorochalima.pdf

11. Carisio CM. Chico Xavier, caridade e o mundo de César: um olhar sobre o modo de gestão da assistência social em Uberaba-MG [Internet]. [dissertação]. Uberlândia, MG: Universidade Federal de Uberlândia; 2008 [citado em 26 mar 2017]. Disponível em: https://repositorio.ufu.br/bitstream/123456789/11916/1/Camila.pdf

12. Camurça MA. O Brasil religioso que emerge do censo 2010: consolidações, tendências e perplexidades. In: Teixeira F, Menezes R. organizadores. Religiões em movimento: o censo de 2010. Petrópolis: Vozes; 2012. p. 63-87.

13. Cunha LA. Saberes e religiosidades de benzedeiras. Anais dos Simpósios da Associação Brasileira de História das Religiões [Internet]. 2012 [citado em 12 nov 2018]. Disponível em: https://docplayer.com.br/78777743-Saberes-e-religiosidades-de-benzedeiras.html

14. Nascimento LC, Oliveira FCS, Santos TFM, Pan R, Flória-Santos M, Alvarenga WA, et al. Atenção às necessidades espirituais na prática clínica de enfermeiros. Aquichán [Internet]. 2016 [citado em 7 maio 2018]; 16(2):179-92. Disponível em: http://www.scielo.org.co/pdf/aqui/v16n2/v16n2a06.pdf. DOI: http://dx.doi.org/10.5294/aqui.2016.16.2.6

15. Salgado APA, Rocha RM, Conti CC. 0 enfermeiro e a abordagem das questões religiosas. Rev Enferm UERJ [Internet]. 2007 [citado em 18 jul 2018]; 15(2):223-8. Disponível em: http://www.facenf.uerj.br/v15n2/v15n2a11.pdf

16. Silva TR, Motta RF. A percepção dos usuários sobre a política de saúde na atenção básica. Mudanças [Internet]. 2015 [citado em 21 jul 2018]; 23(2):17-25. Disponível em: https://www.metodista.br/revistas/revistas-ims/index.php/MUD/article/view/4709. $\quad$ DOI: http://dx.doi.org/10.15603/2176-1019/mud.v23n2p17-25

17. Braga GP. Espiritualidade no divã: do tabu à universidade [Internet]. [tese]. Porto Alegre: Universidade Federal do Rio Grande do Sul; 2014 [citado em 12 maio 2017]. Disponível em: https://lume.ufrgs.br/handle/10183/94891

18. Pereira VNA, Klüppel BLP. A cura pela fé: um diálogo entre ciência e religião. Caminhos [Internet]. 2014 [citado em 10 jun 2017]; 12(1):93-104. Disponível em: http://seer.pucgoias.edu.br/index.php/caminhos/article/view/3033 DOI: http://seer.pucgoias.edu.br/index.php/caminhos/article/view/3033/1838

19. Soratto MT, Silva DM, Zugno PI, Daniel R. Espiritualidade e resiliência em pacientes oncológicos. Saúde e Pesqui [Internet]. 2016 [citado em 17 ago 2018]; 9(1):53-63. Disponível em: https://updoc.site/download/espiritualidade-e-resiliencia-em-pacientes_pdf

10.17765/1983-1870.2016v9n1p53-63

20. Luz MT. Cultura contemporânea e medicinas alternativas: novos paradigmas em saúde no fim do século XX. Physis (Rio J.) [Internet]. 2005 [citado em 13 ago 2018]; 15(Supl):145-76. Disponível em: http://www.scielo.br/pdf/physis/v15s0/v15s0a08.pdf

21. Martins SR, Pereira FW, Acosta DF, Amorim CB. Representações sociais de profissionais da saúde acerca das plantas medicinais. Rev Cuba Enferm [Internet]. 2017 [citado em 10 maio 2018]; 33(2):[html]. $\quad$ Disponível http://www.revenfermeria.sld.cu/index.php/enf/article/view/1065/258 
22. Fernandes MG. A medicina centrada na pessoa: o componente espiritual na abordagem pelo médico de família e comunidade [Internet]. [tese]. Rio de Janeiro: Escola Nacional de Saúde Pública Sergio Arouca; 2015 [citado em 24 maio 2017]. Disponível em: https://www.arca.fiocruz.br/bitstream/icict/13459/1/ve_Mariana_Gomes_ENSP_2015.pdf 23. Oliveira ATSA, Moreira CT, Machado CA, Vasconcelos Neto JA, Machado MFAS. Crendices e práticas populares: influência na assistência de enfermagem prestada à criança no programa saúde da família. Rev Bras Promoç Saúde [Internet]. 2005 [citado em 17 jul 2018]; 19(1):11-8. Disponível em: http://www.redalyc.org/articulo.oa?id=40819104

24. Marin RC, Scorsolini-Comin F. Desfazendo o "mau-olhado": magia, saúde e desenvolvimento no ofício das benzedeiras. Psicol Ciênc Prof. [Internet]. 2017 [citado em 28 out 2017]; 37(2):446-60. Disponível em: http://www.scielo.br/pdf/pcp/v37n2/1982-3703-pcp-37-2-0446.pdf

25. Soares AN, Morgan BS, Santos FBO, Matozinhos FP, Penna CMM. Crenças e práticas de saúde no cotidiano de usuários da rede básica de saúde. Rev Enferm UERJ [Internet]. 2014 [citado em 13 maio 2018]; 22(1):83-8. Disponível em: http://www.epublicacoes.uerj.br/index.php/enfermagemuerj/article/view/11450

26. Medeiros REG, Nascimento EGC, Diniz GMD, Alchieri JC. Na simplicidade a complexidade de um cuidar: a atuação da benzedeira na atenção à saúde da criança. Physis (Rio J.) [Internet]. 2013 [citado em 6 nov 2017]; 23(4):1339-57. Disponível em: http://www.scielo.br/pdf/physis/v23n4/16.pdf. DOI: http://dx.doi.org/10.1590/S010373312013000400016

27. Arrieira ICO, Thofehrn MB, Porto AR, Moura PMM, Martins CL, Jacondino MB. Espiritualidade nos cuidados paliativos: experiência vivida de uma equipe interdisciplinar. Rev Esc Enferm USP [Internet]. 2017 [citado em 2 jul 2018]; 52:e03312 [8 p.]. Disponível em: http://www.scielo.br/pdf/reeusp/v52/0080-6234-reeusp-S1980-220X2017007403312.pdf. DOI: http://dx.doi.org/10.1590/S1980-220X2017007403312

28. Siqueira KM, Barbosa MA, Brasil VV, Oliveira LMC, Andraus LMS. Crenças populares referentes à saúde: apropriação de saberes sócio-culturais. Texto \& Contexto Enferm. [Internet]. 2006 [citado em 14 jul 2018]; 15(1):68-73. Disponível em: http://www.scielo.br/pdf/tce/v15n1/a08v15n1.pdf. DOI: http://dx.doi.org/10.1590/S0104-07072006000100008

29. Tesser CD, Pezzato LM, Silva EN. Medicalização social e odontologia: possíveis aproximações. Saúde Soc. [Internet]. 2015 [citado em 12 ago 2018]; 24(4):1349-61. Disponível em: http://www.scielo.br/pdf/sausoc/v24n4/1984-0470-sausoc-24-04-01349.pdf. DOI: 10.1590/S0104-12902015136108

\section{CONTRIBUIÇÕES}

Janaína Aparecida Maia Silva e Luiza Maria Assunção participaram da concepção, coleta e análise dos dados, redação e revisão. Leiner Resende Rodrigues colaborou na concepção, coleta e análise dos dados e revisão.

\section{Como citar este artigo (Vancouver)}

Silva JAM, Assunção LM, Rodrigues LR. Benzedura na Estratégia Saúde da Família: perspectivas de profissionais da enfermagem. REFACS [Internet]. 2020 [citado em inserir dia, mês e ano de acesso]; 8(1):87-99. Disponível em: inserir link de acesso. DOI: inserir link do DOI.

\section{Como citar este artigo (ABNT)}

SILVA, J. A. M.; ASSUNÇÃO, L. M.; RODRIGUES, L. R. Benzedura na Estratégia Saúde da Família: perspectivas de profissionais da enfermagem. REFACS, Uberaba, MG, v. 8, n. x, p. 87-99, 2020. Disponível em: inserir link de acesso. Acesso em: inserir dia, mês e ano de acesso. DOI: inserir link do DOI.

\section{Como citar este artigo (APA)}

Silva, J.A.M., Assunção, L.M. \& Rodrigues, L.R. (2020). Benzedura na Estratégia Saúde da Família: perspectivas de profissionais da enfermagem. REFACS, 8(1), 87-99. Recuperado em inserir dia, mês e ano de acesso de inserir link de acesso. DOI: inserir link do DOI. 